\title{
EFFECT OF GRAIN REFINEMENT ON MECHANICAL PROPERTIES OF MICROALLOYED STEELS
}

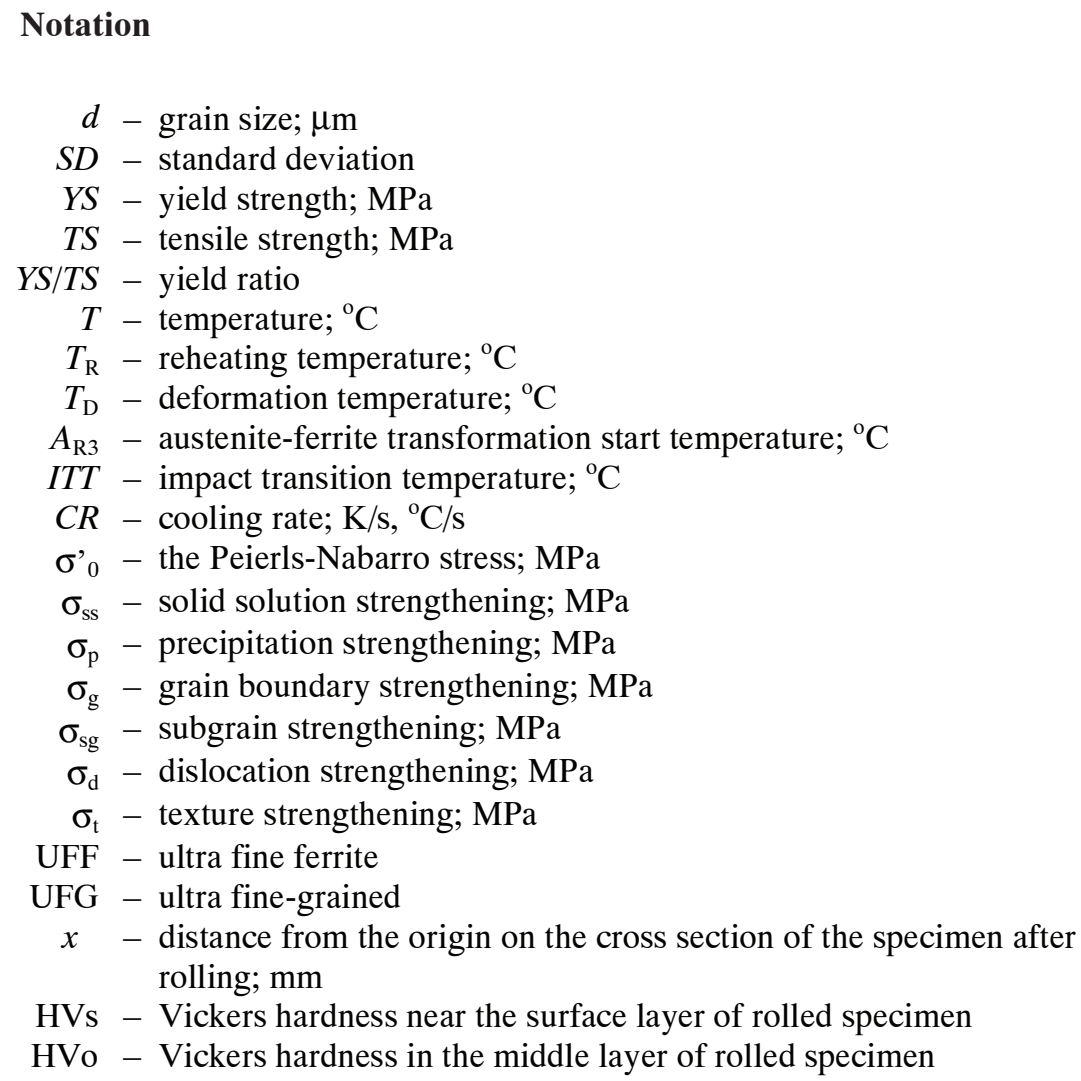

* M.Sc.; ** Ph.D., D.Sc.: Faculty of Metals Engineering and Industrial Computer Science, AGH University of Science and Technology, Krakow, Poland; muszka@agh.edu.pl; majta@metal.agh.edu.pl 


\section{INTRODUCTION}

The grain refinement is one of the most effective strengthening mechanism, improving mechanical properties without loss in ductility. It is well known, however, that proper prediction of mechanical properties of fine grained materials is much more complicated because of different deformation and strengthening mechanisms operating in these materials. When the strong grain refinement (below 1 micron) is achieved, some deviations, comparing to the conventional materials have been reported i.e. change in Hall-Petch slope [1], different deformation and fracture mechanisms [2,3], enhanced strain rate sensitivity or lack in the work $[4,5]$. Unfortunately, these phenomena and their physical basis are still poorly understood and most of the well known constitutive laws (i.e. Hall-Petch relationship) are no longer effective in description of the deformation process of such materials. Thus, the proper understanding of specific mechanisms by which the plastic deformation leads to a refined grain size is of paramount importance.

There is a need to systematically correlate chemical composition, the evolution of deformation microstructure, amount of deformation, heat treatment profile, average grain size distribution and texture on the deformation mechanisms operating in submicron/nano materials during processing. Moreover, reliable constitutive description allowing to predict mechanical behavior of very fine-grained materials seems to be very important issue.

It is well known that specific mechanical properties of metal products are the basic requirements from the receiver's point of view. These properties can be obtained as a result of a number of strengthening mechanisms, which act together during deformation process. Depending on chemical composition of the material, type of crystallographic lattice, and deformation parameters they could be classified as [6]:

- the Peierls-Nabarro stress due to the inherent friction stress of the material which must be exceeded to allow easy dislocation glide, $\sigma_{0}^{\prime}$;

- solid solution strengthening (alloying elements), $\sigma_{\mathrm{ss}}$;

- dispersion strengthening (precipitation hardening), $\sigma_{\mathrm{p}}$;

- grain boundary and subgrain strengthening, $\sigma_{\mathrm{g}}, \sigma_{\mathrm{sg}}$;

- dislocations strengthening (from forest of dislocations), $\sigma_{d}$;

- textural strengthening, $\sigma_{\mathrm{t}}$.

The contribution of strengthening components strongly depends on the chemical composition of the material, its deformation history and resulting microstructure.

It is well known, that amongst the different methods of mechanical properties improvement, only strong grain refinement leads to an increase in strength of the material without any significant drop in its toughness and ductility. Moreover, this strengthening method seems to be especially attractive because it doesn't require a usage of expensive alloy additions and still existing production technology can be used. For example, obtaining the UFF structure in low carbon steel, beside the increase in mechanical properties, leads also to decrease in the ITT temperature and improves the weldability, whereas in microalloyed steel leads to additional increase in its strength. 


\section{EXPERIMENTAL PROCEDURES}

In the present study, the influence of grain size on mechanical properties was studied. The low carbon and microalloyed steels have been selected. The chemical compositions are summarized in Table 1. The range of different grain sizes was developed using single-pass hot rolling experiments. Samples had dimensions $140 \times 40 \times 15 \mathrm{~mm}$ (length, width, thickness). The deformation schedules were evaluated in order to involve different phenomena (static and dynamic recrystallization, dynamic strain induced transformation) using thermomechanical treatment and finally to obtain the range of grain sizes from approx. 12 down to 2 micrometers. The $T_{\mathrm{R}}$ temperature was determined as follows: samples were austenitized at different temperatures $\left(900,950,1000,1050^{\circ} \mathrm{C}\right)$ for $300 \mathrm{~s}$, then quenched and polished. Their microstructures were revealed using picric acid solution. The austenite grain size was then measured using mean linear intercepts method. The temperatures were chosen in order to prevent the grain growth during reheating.

Table 1. Chemical composition of investigated steels

\begin{tabular}{|c|c|c|c|c|c|c|c|c|c|c|c||}
\hline Steel & $\mathrm{C}$ & $\mathrm{Mn}$ & $\mathrm{Si}$ & $\mathrm{Nb}$ & $\mathrm{Ti}$ & $\mathrm{V}$ & $\mathrm{Al}$ & $\mathrm{Mo}$ & $\mathrm{Cu}$ & $\mathrm{Cr}$ & $\mathrm{Ni}$ \\
\hline $\mathrm{A}(250)$ & 0.15 & 1.0 & 0.14 & 0.0015 & 0.002 & 0.002 & 0.031 & 0.002 & 0.011 & 0.016 & 0.022 \\
\hline $\mathrm{B}(\mathrm{X} 65)$ & 0.07 & 1.6 & 0.31 & 0.07 & 0.02 & 0.01 & 0.035 & 0.3 & 0.02 & 0.02 & 0.03 \\
\hline
\end{tabular}

The continuous cooling deformation procedure was carried out to determine the $\mathrm{Ar}_{3}$ temperature for a given thermomechanical condition using hot torsion testing. The steel was reheated to a given austenitization temperature and held for a given time. This method has been described in [7]. It was then cooled down at a constant cooling rate of $0.5 \mathrm{~K} / \mathrm{s}$ to a temperature that was higher than any critical temperature encountered during cooling from the reheat temperature. A constant strain rate $\left(0.001 \mathrm{~s}^{-1}\right)$ was then applied continuously and the sample was further cooled at $0.5 \mathrm{~K} / \mathrm{s}$ until the specimen temperature dropped significantly below the $A_{\mathrm{r} 3}$. The $A_{\mathrm{r} 3}$ temperatures were found to be $778^{\circ} \mathrm{C}$ for steel $\mathrm{A}$ and $799^{\circ} \mathrm{C}$ for steel B.

The rolling tests were carried out according to the schedule showed in Tables 2 and 3.

Table 2. Thermomechanical treatment parameters for steel A

\begin{tabular}{|c|c|c|c|c||}
\hline Specimen & $\begin{array}{c}T_{\mathrm{R}}, \\
{ }^{\circ} \mathrm{C}\end{array}$ & $\begin{array}{c}T_{\mathrm{D}}, \\
{ }^{\circ} \mathrm{C}\end{array}$ & Strain & $\begin{array}{c}C R, \\
{ }^{\circ} \mathrm{C} / \mathrm{s}\end{array}$ \\
\hline A1 & 900 & 900 & $0.51(40 \%)$ & 0.2 \\
\hline A2 & 1200 & 750 & $0.91(60 \%)$ & 4 \\
\hline A3 & 900 & 778 & $0.51(40 \%)$ & 10 \\
\hline A4 & 900 & 800 & $0.51(40 \%)$ & 10 \\
\hline A5 & 900 & 800 & $0.70(50 \%)$ & 10 \\
\hline A6 & 1200 & 750 & $1.35(74 \%)$ & 10 \\
\hline A7 & 900 & 800 & $1.35(74 \%)$ & 10 \\
\hline
\end{tabular}


Table 3. Thermomechanical parameters for steel B

\begin{tabular}{|c|c|c|c|c||}
\hline Specimen & $\begin{array}{c}T_{\mathrm{R}}, \\
{ }^{\circ} \mathrm{C}\end{array}$ & $\begin{array}{c}T_{\mathrm{D}}, \\
{ }^{\circ} \mathrm{C}\end{array}$ & Strain & $\begin{array}{c}C R, \\
{ }^{\circ} \mathrm{C} / \mathrm{s}\end{array}$ \\
\hline B1 & 1200 & 1000 & $1.05(65 \%)$ & 0.2 \\
\hline B2 & 1200 & 800 & $1.05(65 \%)$ & 0.2 \\
\hline B3 & 1200 & 800 & $1.05(65 \%)$ & 4 \\
\hline B4 & 1200 & 840 & $1.20(70 \%)$ & 4 \\
\hline B5 & 1000 & 840 & $1.31(73 \%)$ & 4 \\
\hline B6 & 1000 & 800 & $1.31(73 \%)$ & 4 \\
\hline
\end{tabular}

Samples were heated to the reheating temperature $T_{\mathrm{R}}$, held for $300 \mathrm{~s}$ then cooled to deformation temperature $T_{\mathrm{D}}$ and rolled. After deformation samples were cooled down to the room temperature using different cooling rates (different cooling mediums had been used: water quenching, air cooling, Super Quench oil, kaowool blanket). The temperature of all rolled samples was measured continuously during the tests by N-type thermocouples, inserted at different positions in the side of samples.

From all strips after rolling samples for microstructure analysis were cut, both in the rolling and transversal direction. The samples then were polished and etched using $2 \%$ Nital in order to reveal ferrite microstructures. The grain size measurements were carried out using mean linear intercepts method. At least 300 grains were counted.

The quasi-static mechanical properties were measured using the MTS machine. Two samples were cut from each rolled strip in the rolling direction. The shape and dimensions of the tensile samples are shown in Figure 1a.

a)

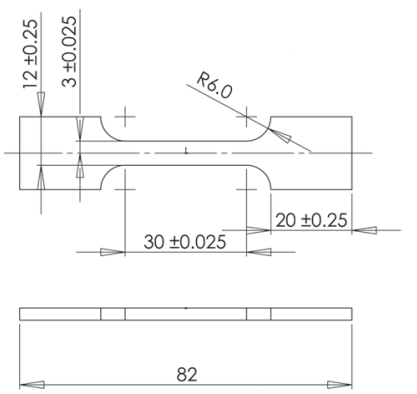

b)

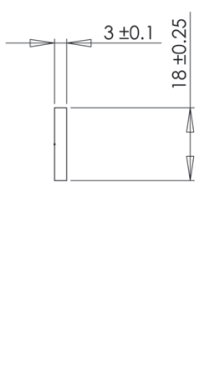

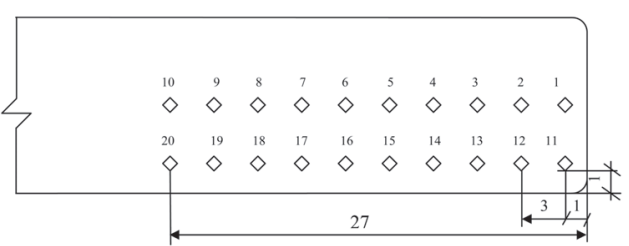

Fig. 1. Tensile sample dimensions (a) indentations distribution for Vickers hardness measurements in specimens after rolling (b)

In order to study the microstructural and mechanical inhomogeneity of rolled specimens, Vickers hardness measurements $(5 \mathrm{kG})$ were carried out on the cross section in transversal direction to the rolling plane. The measurements were performed according to Figu- 
re $1 \mathrm{~b}$ i.e. in the middle of the cross section and near the surface layer. First indentation was done in the middle layer of the transversal cross section, in the distance of $1 \mathrm{~mm}$ from the specimen's edge, and the following ones were done every $3 \mathrm{~mm}$. Similarly, measurements have been carried out in the layer near to the specimen's surface ( $1 \mathrm{~mm}$ from the surface). Next, in order to estimate the mechanical properties inhomogeneity level, the diagrams of HV5 vs. distance from the origin. Also, the HVs/HVo for all the specimens from both steels. The example results are shown in Figures 5 and 6. Basic observations, concerning effect of grain size, chemical composition, and thermomechanical history on microstructural and mechanical inhomogeneity are summarized in Table 6 .

\section{RESULTS}

The influence of thermomechanical parameters on grain refinement is clearly shown in Figure 2, which presents chosen microstructures of A steel after hot rolling experiments. The optical microphotographs were taken in the rolling direction. The strongest refinement of the microstructure was achieved for sample deformed just above $A_{\mathrm{r} 3}$ temperature (Fig. 2b). Samples deformed after reheating to higher $T_{\mathrm{R}}$ temperature (with more coarse austenite initial structure) have more inhomogeneous structures than samples with finer initial austenite microstructure. The increase in strain caused also grain refinement, however even strain of 1.35 ( $74 \%$ of reduction) was insufficient to obtain strain induced dynamic transformation ferrite. Thus, more experiments towards further grain refinement including multipass rolling are necessary.

a)

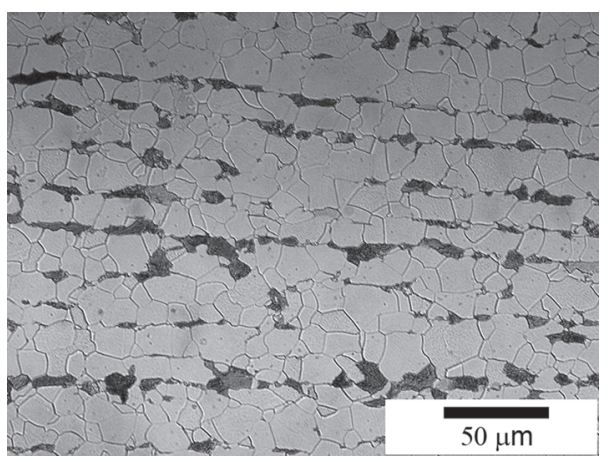

b)

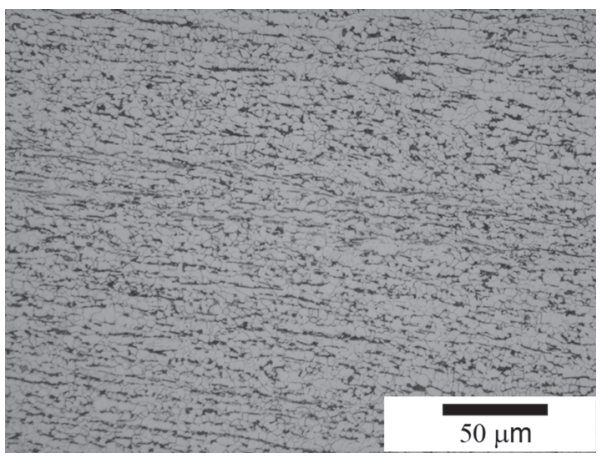

Fig. 2. Examples of microstructures after hot rolling of A steel: specimen A1 (a); specimen A7 (b)

Similar results were obtained for microalloyed steel. Figure 3 shows its chosen microstructures after hot rolling. The effect of deformation parameters (reheating and deformation temperature, strain) in general is similar comparing to the previous grade of steel. However, the level of grain refinement achieved in this case (specimen B6) was lower, what may be caused by decreased cooling rate. 
a)

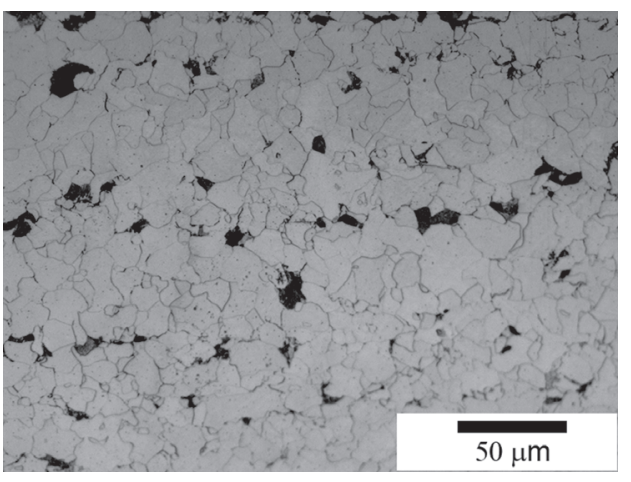

b)

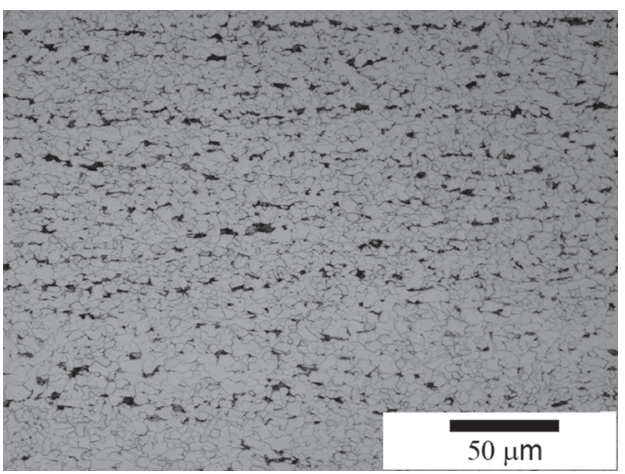

Fig. 3. Examples of microstructures after hot rolling of B steel: specimen B1 (a); B6 (b)

Results of grain size measurements and quasi-static tensile test are summarized in Tables 4 and 5. Figure 4 shows the grain size vs. yield strength $(Y S)$ and tensile strength $(T S)$ for both steel grades. Presented here results of low carbon steel (steel A) are typical i.e. the Hall-Petch slope seems to be reasonable both for $Y S$ and TS. Some deviation is observed in the case of microalloyed steel (steel B). In this case the precipitation hardening phenomena as well as solid solution strengthening seems to influence the mechanical behavior of the specimens.

Table 4. Results of grain size measurements and quasi-static tensile test of A steel

\begin{tabular}{|c|c|c|c|c||}
\hline Specimen & $\begin{array}{c}d(S D), \\
\mu \mathrm{m}\end{array}$ & $\begin{array}{c}Y S, \\
\mathrm{MPa}\end{array}$ & $\begin{array}{c}T S, \\
\mathrm{MPa}\end{array}$ & $Y S / T S$ \\
\hline $\mathrm{A} 1$ & $12.79(6.58)$ & 288 & 443 & 0.65 \\
\hline $\mathrm{A} 2$ & $10.81(5.87)$ & 376 & 498 & 0.76 \\
\hline $\mathrm{A} 3$ & $7.57(5.84)$ & 400 & 530 & 0.76 \\
\hline A4 & $6.12(3.34)$ & 388 & 505 & 0.77 \\
\hline A5 & $5.22(2.85)$ & 392 & 523 & 0.75 \\
\hline A6 & $3.96(2.14)$ & 431 & 552 & 0.78 \\
\hline A 9 & $2.44(1.48)$ & 500 & 551 & 0.91 \\
\hline
\end{tabular}

Table 5. Results of grain size measurements and quasi-static tensile test of B steel

\begin{tabular}{|c|c|c|c|c||}
\hline Specimen & $\begin{array}{c}d(S D), \\
\mu \mathrm{m}\end{array}$ & $\begin{array}{c}Y S, \\
\mathrm{MPa}\end{array}$ & $\begin{array}{c}T S, \\
\mathrm{MPa}\end{array}$ & $Y S / T S$ \\
\hline B1 & $12.34(6.11)$ & 395 & 489 & 0.81 \\
\hline B2 & $10.09(6.01)$ & 463 & 524 & 0.88 \\
\hline B3 & $8.53(5.05)$ & 502 & 561 & 0.90 \\
\hline B4 & $5.28(3.53)$ & 504 & 563 & 0.89 \\
\hline B5 & $4.13(2.14)$ & 400 & 483 & 0.83 \\
\hline B6 & $3.02(1.53)$ & 450 & 509 & 0.88 \\
\hline
\end{tabular}


Two samples with the smallest grain size were reheated to lower $T_{\mathrm{R}}\left(1000^{\circ} \mathrm{C}\right)$, which caused that less amount of $\mathrm{Nb}$ dissoluted and, therefore, had less precipitation hardening effect.

a)

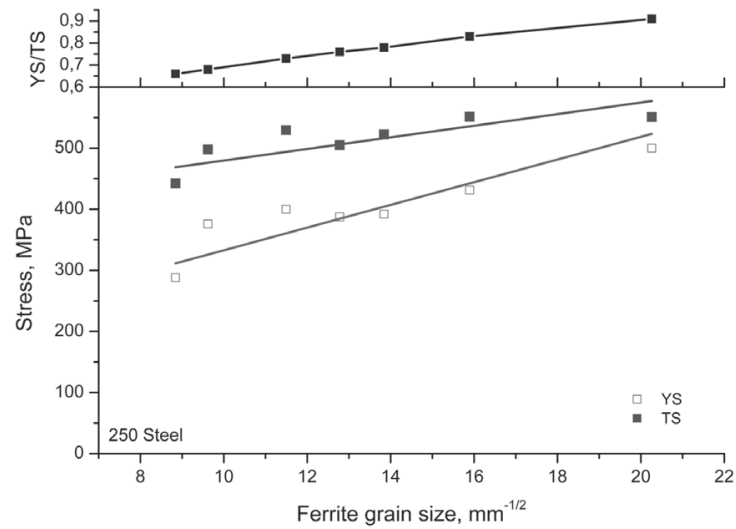

b)

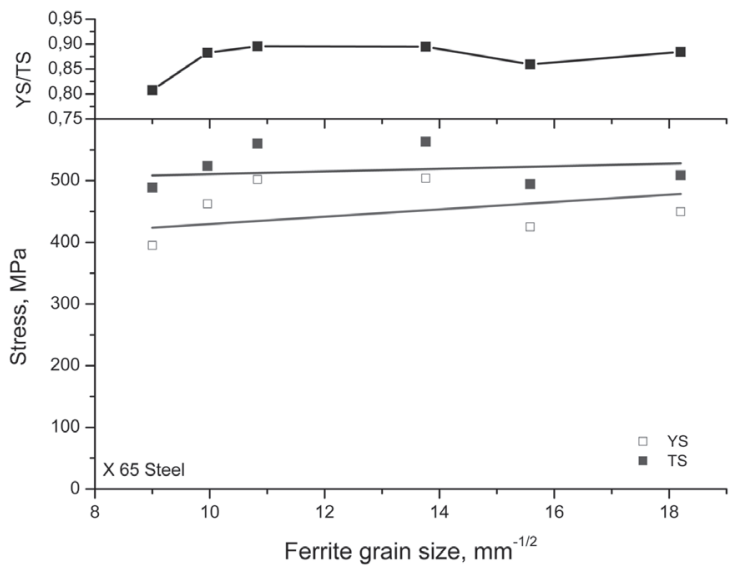

Fig. 4. Measurements of yield strength, tensile strength and yield ratio vs. grain size - A steel (a); B steel (b)

Basing on hardness measurements performed at the cross section of rolled specimens (in transversal direction to RD), it can be concluded that specimens with more coarse structure represent higher inhomogeneity of mechanical properties. Specimens, where the structure refinement level was significantly higher, have more homogeneous microstructure as well as mechanical properties along the measured distance (see Fig. 5 and 6).

Simultaneously, much higher properties are observed in these specimens near the surface layer, what can be attributed to the application of increased deformation (approx. 1.3) that involves high shear stresses, having principal influence on microstructural effects. Very often similar shear stresses are used in obtaining nanocrystalline and nanostructural materials using severe plastic deformation techniques [8-10]. 

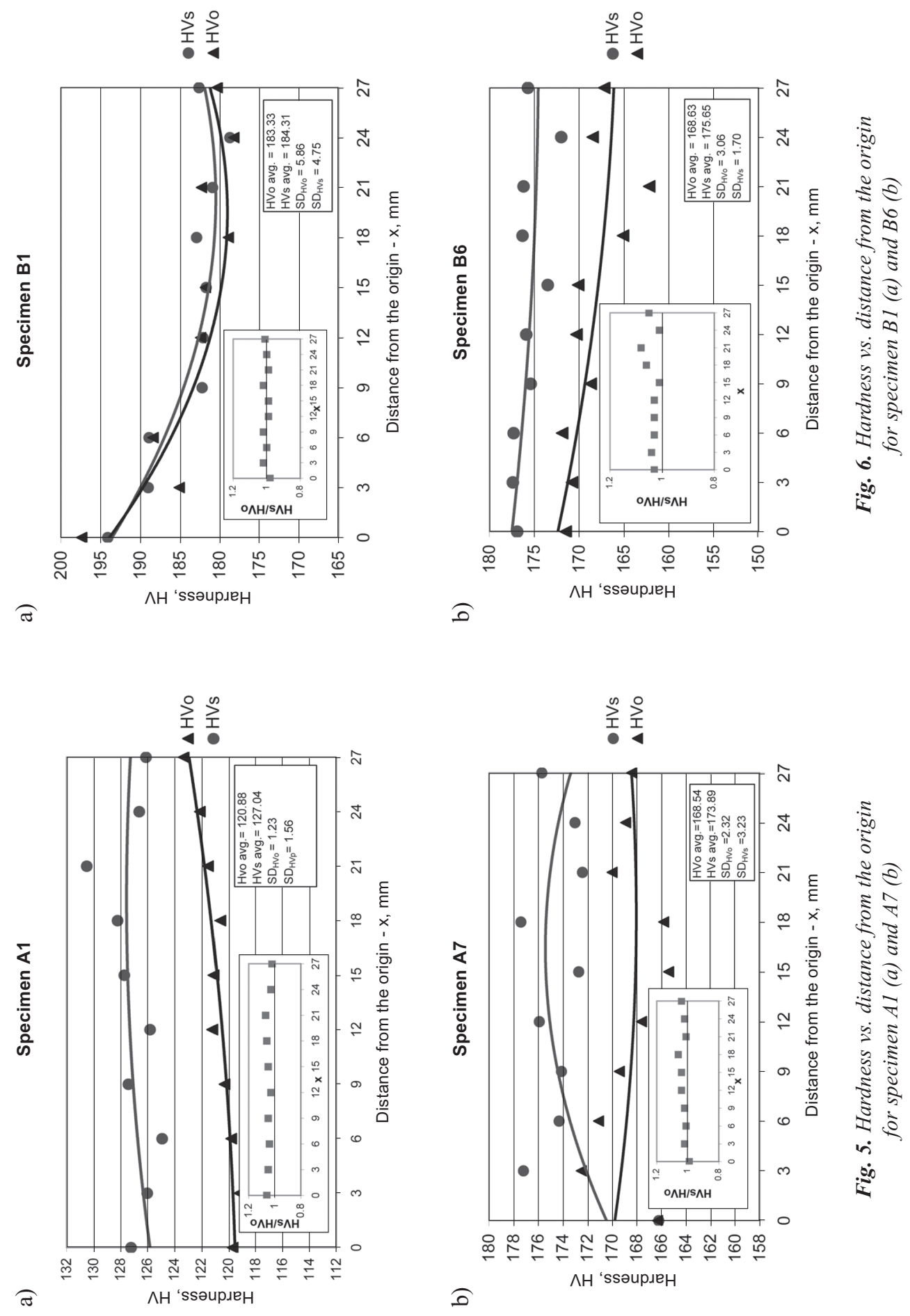
Examples of stress-strain curves obtained in quasi-static tensile tests are presented in Figure 7. Mechanical behavior of analyzed here specimens is a summary of the effect of finish deformation temperature, strain and cooling rate on the ferrite grains observed within the final structure. Presented in Figure 7 results indicate that for both steels the thermomechanical history can effectively affect the mechanical properties, first of all the strength.

a)

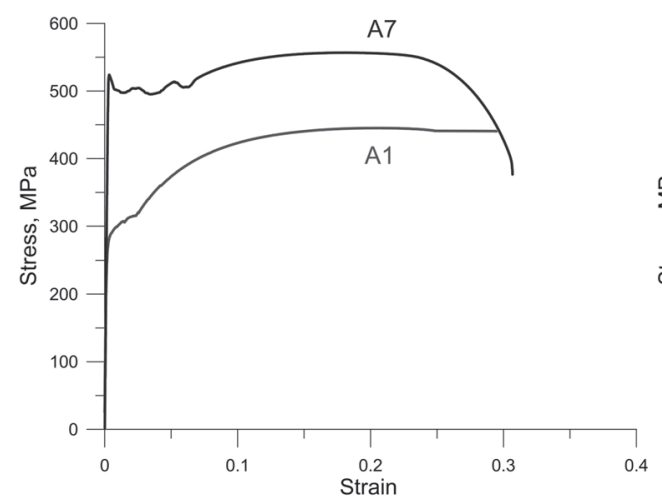

b)

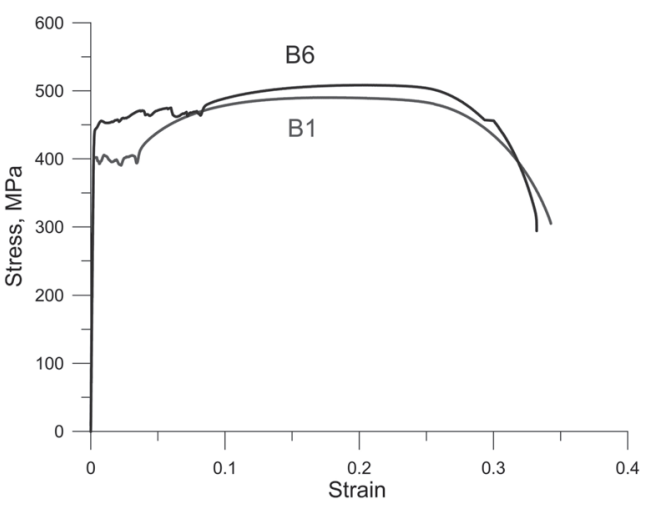

Fig. 7. Quasi-static tensile test results for selected specimens: A1, A7 (a) and B1, B6 (b)

Table 6 summarizes all of the original observations collected during present analysis. It can be stated that obtained by termomechanical treatment grain refinement leads improved mechanical properties and also to increased homogeneity of the final microstructure.

Table 6. Effect of chemical composition and thermomechanical processing on mechanical properties, mechanical properties inhomogeneity and microstructure of the investigated steels

\begin{tabular}{|c|l|l|l||}
\hline Specimen & \multicolumn{1}{|c|}{ Mechanical properties, HV } & \multicolumn{1}{|c||}{ Properties homogeneity } & Microstructure \\
\hline 1 & \multicolumn{1}{|c|}{2} & \multicolumn{1}{|c||}{4} \\
\hline A1 & $\begin{array}{l}\text { Increase of HVs i HVo along the } \\
\text { measured distance. Homogeneous } \\
\text { increase of HVp/HVo }\end{array}$ & $\begin{array}{l}\text { Constant increase of HVs } \\
\text { and HVo along measured } \\
\text { distance }\end{array}$ & $\begin{array}{l}\text { Coarse-grained, } \\
\text { homogeneous }\end{array}$ \\
\hline A2 & $\begin{array}{l}\text { Increase of HVs, decrease of HVo } \\
\text { along measured distance. Inhomo- } \\
\text { geneous increase of HVs/HVo }\end{array}$ & $\begin{array}{l}\text { Inhomogeneous increase of } \\
\text { HVs along measured distance, } \\
\text { inhomogeneous decrease of } \\
\text { HVo along measured distance }\end{array}$ & $\begin{array}{l}\text { Coarse-grained, } \\
\text { homogeneous }\end{array}$ \\
\hline A3 & $\begin{array}{l}\text { Decrease of HVs and HVo along } \\
\text { measured distance. Inhomogeneous } \\
\text { increase of HVs/Hvo }\end{array}$ & $\begin{array}{l}\text { Constant decrease } \\
\text { of HVs and HVo along } \\
\text { measured distance }\end{array}$ & $\begin{array}{l}\text { Inhomogeneous: } \\
\text { coarse- and fine- } \\
\text { grained }\end{array}$ \\
\hline
\end{tabular}


Table 6 cont

\begin{tabular}{|c|c|c|c|}
\hline Specimen & Mechanical properties, HV & Properties homogeneity & Microstructure \\
\hline 1 & 2 & 3 & 4 \\
\hline A4 & $\begin{array}{l}\text { Increase of HVo, decrease of HVs } \\
\text { along measured distance. Inhomo- } \\
\text { geneous decrease of HVs/Hvo }\end{array}$ & $\begin{array}{l}\text { Inhomogeneous increase of } \\
\text { HVo along measured distance, } \\
\text { inhomogeneous decrease of } \\
\text { HVs along measured distance }\end{array}$ & $\begin{array}{l}\text { Fine-grained, } \\
\text { homogeneous }\end{array}$ \\
\hline A5 & $\begin{array}{l}\text { Inhomogeneous increase of HVo, } \\
\text { inhomogeneous decrease of HVs } \\
\text { along measured distance. Inhomo- } \\
\text { geneous increase of HVs/Hvo }\end{array}$ & $\begin{array}{l}\text { Initial increase, later decrease } \\
\text { of HVs. Initial decrease, later } \\
\text { increase of HVo along } \\
\text { measured distance }\end{array}$ & $\begin{array}{l}\text { Fine-grained, } \\
\text { homogeneous }\end{array}$ \\
\hline A6 & $\begin{array}{l}\text { Inhomogeneous decrease of HVs } \\
\text { and HVo Along measured distance. } \\
\text { Almost constant ratio of HVs/HVo }\end{array}$ & $\begin{array}{l}\text { Initial increase, later decrease } \\
\text { of both HVs and HVo along } \\
\text { measured distance }\end{array}$ & $\begin{array}{l}\text { Fine-grained, } \\
\text { homogeneous }\end{array}$ \\
\hline A7 & $\begin{array}{l}\text { Inhomogeneous increase of HVs, } \\
\text { inhomogeneous decrease of HVo } \\
\text { along measured distance. Inhomo- } \\
\text { geneous increase of HVs/HVo }\end{array}$ & $\begin{array}{l}\text { Initial increase, later decrease } \\
\text { of HVs. Decrease of HVo } \\
\text { along measured distance }\end{array}$ & $\begin{array}{l}\text { Ultra fine- } \\
\text { grained, } \\
\text { homogeneous }\end{array}$ \\
\hline B1 & $\begin{array}{l}\text { Increase of HVo and decrease of } \\
\text { HVs along measured distance. } \\
\text { Inhomo-geneous decrease of } \\
\text { HVs/HVo }\end{array}$ & $\begin{array}{l}\text { Inhomogeneous increase } \\
\text { of HVo and inhomogeneous } \\
\text { decrease of HVs along } \\
\text { measured distance }\end{array}$ & $\begin{array}{l}\text { Coarse-grained, } \\
\text { inhomogeneous }\end{array}$ \\
\hline B2 & $\begin{array}{l}\text { Decrease of } \mathrm{HVs} \text { and } \mathrm{HVo} \text { along } \\
\text { measured distance. Inhomogeneous } \\
\text { increase of } \mathrm{HVs} / \mathrm{HVo}\end{array}$ & $\begin{array}{l}\text { Inhomogeneous decrease } \\
\text { of both HVs and HVo along } \\
\text { measured distance }\end{array}$ & $\begin{array}{l}\text { Coarse-grained, } \\
\text { homogeneous }\end{array}$ \\
\hline B3 & $\begin{array}{l}\text { Inhomogeneous decrease of } \mathrm{HVp} \\
\text { and HVo along measured distance. } \\
\text { Insignificant increase of } \mathrm{HVs} / \mathrm{HVo}\end{array}$ & $\begin{array}{l}\text { Initial, decrease and later } \\
\text { increase of HVs and HVo } \\
\text { along measured distance }\end{array}$ & $\begin{array}{l}\text { Coarse-grained, } \\
\text { homogeneous }\end{array}$ \\
\hline B4 & $\begin{array}{l}\text { Decrease of HVo and HVs along } \\
\text { measured distance. Homogeneous } \\
\text { increase of HVs/HVo }\end{array}$ & $\begin{array}{l}\text { Inhomogeneous decrease } \\
\text { of HVo and HVs along } \\
\text { measured distance }\end{array}$ & $\begin{array}{l}\text { Fine-grained, } \\
\text { homogeneous }\end{array}$ \\
\hline B5 & $\begin{array}{l}\text { Clear increase of } \mathrm{HVs} \text { and } \mathrm{HVo} \\
\text { along measured distance. } \\
\text { Homogeneous increase of } \mathrm{HVs} / \mathrm{HVo}\end{array}$ & $\begin{array}{l}\text { Initial decrease and later } \\
\text { increase of HVp and HVo }\end{array}$ & $\begin{array}{l}\text { Fine-grained, } \\
\text { homogeneous }\end{array}$ \\
\hline B6 & $\begin{array}{l}\text { Decrease of HVs and HVo along } \\
\text { measured distance. Significantly } \\
\text { higher value of HVs. Inhomoge- } \\
\text { neous increase of HVs/HVo }\end{array}$ & $\begin{array}{l}\text { Constant decrease of HVs } \\
\text { and HVo along measured } \\
\text { distance }\end{array}$ & $\begin{array}{l}\text { Ultra fine- } \\
\text { grained, } \\
\text { homogeneous }\end{array}$ \\
\hline
\end{tabular}




\section{CONCLUSIONS}

The experimental results confirm the previous theoretical assumptions and show that the mechanical response of low carbon and microalloyed steels strongly depends on termomechanical history and ferrite grain size. In the case of quasi-static deformation, the mechanical properties of the material can be fully controlled by processing parameters (strain, strain rate, deformation temperature and cooling rate). However obtained level of grain refinement didn't cause any significant deviations in material behavior comparing to coarsegrained microstructures. Thus, the next step of study will be focused on obtaining higher level of grain refinement.

\section{Acknowledgements}

The financial support of the Polish Committee for Scientific Research (Research project KBN no. 3 TO8B 042 27) is gratefully acknowledged.

\section{REFERENCES}

[1] Nes E., Marthinsen K., Holmedal B.: The effect of boundary spacing on substructure strengthening. Materials Science and Technology, 20 (2004), pp. 1377-1382

[2] Hansen N.: Boundary strengthening in undeformed and deformed polycrystals. Materials Science and Engineering A, 409 (2005), pp. 39-45

[3] Hansen N.: Hall-Petch relation and boundary strengthening. Scripta Materiala, 51 (2004), p. 801

[4] Majta J., Pietrzyk M., Lenard J.G.: A study of the effect of the thermomechanical history on the mechanical properties of a high niobium steel. Materials Science and Engineering: A, 208 (1996), p. 249

[5] Huang S., Khan A.S.: Modeling the Mechanical Behavior of 1100-0 Aluminum at Different Strain Rates by the Bodner-Partom Model. International Journal of Plasticity, 8 (1992), p. 501

[6] Majta J.: Complete model for niobium-microalloyed steels deformed under hot working conditions. Thermomechanical Processing of Steels, London, 2000, IOM Communications, The Chameleon Press Ltd., Vol. 1, p. 322

[7] Belladi H.: Ultrafine Ferrite Formation in Steels Through Thermomechanical Processing. Ph.D. Thesis, Deakin University, Geelong, Vict, Australia 2004

[8] Umemoto M., Todaka Y., Tschuiya K.: Nanocrystallization of Steels by Various Severe Plastic Deformation. MS\&T 2003, Processing and Properties of Structural Nanomaterials, pp. 126-132

[9] Inoue K., Tsui N., Saito Y.: Ultra-Grain Refinement of 36\%Ni Steel by Accumulative Roll-Bonding (ARB) Process. (ISUG 2001), Eds. S. Takaki and T. Maki, Fukuoka, Japan, 2001, pp. 126-129

[10] Lowe T.C., Valiev R.Z.: The use of Severe Plastic Deformation Techniques in grain refinement. JOM A publication of The Minerals, Metals \& Materials Society, October 2004, pp. 64-68

Received

December 2006 
